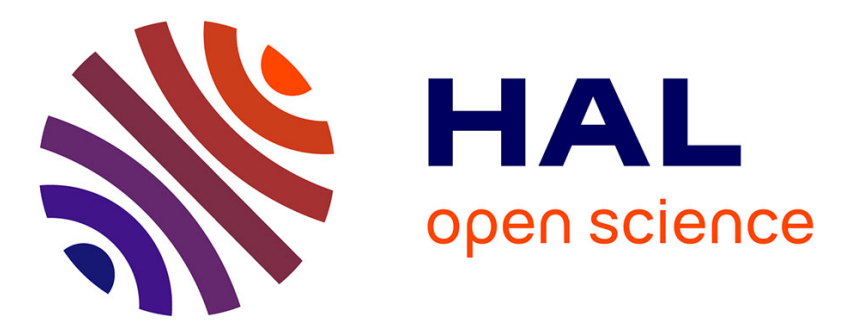

\title{
Development of an empirical aging model for Li-ion batteries and application to assess the impact of V2G strategies on battery lifetime
}

\author{
Martin Petit, Eric Prada, Valérie Sauvant-Moynot
}

\section{To cite this version:}

Martin Petit, Eric Prada, Valérie Sauvant-Moynot. Development of an empirical aging model for Li-ion batteries and application to assess the impact of V2G strategies on battery lifetime. Applied Energy, 2016, 172 (June), pp.398-407. 10.1016/j.apenergy.2016.03.119 . hal-01394977

\section{HAL Id: hal-01394977 \\ https://hal.science/hal-01394977}

Submitted on 10 Nov 2016

HAL is a multi-disciplinary open access archive for the deposit and dissemination of scientific research documents, whether they are published or not. The documents may come from teaching and research institutions in France or abroad, or from public or private research centers.
L'archive ouverte pluridisciplinaire HAL, est destinée au dépôt et à la diffusion de documents scientifiques de niveau recherche, publiés ou non, émanant des établissements d'enseignement et de recherche français ou étrangers, des laboratoires publics ou privés. 


\section{Development of an empirical aging model for Li-ion batteries and application to assess the impact of V2G strategies on battery lifetime}

Martin Petit, Eric Prada, Valérie Sauvant-Moynot

IFP Energies nouvelles, Rond-point de l'échangeur de Solaize, BP3, 69360 Solaize

\section{Abstract}

In this paper an empirical capacity fade model for Li-ion batteries has been developed, calibrated and validated for a NCA/C and a LFP/C Li-ion cell. Based on extensive experimental work, it is able to describe both cycle and calendar effects on aging. The stress factors taken into account for each aging mode are the state of charge and the temperature for calendar aging, and the temperature and the current for cycle aging. A simple approach has been adopted in order to instantaneously apply either cycle aging or calendar aging according to operating conditions and thus accurately model aging effects due to dynamic operating conditions. This model has then been coupled to an electrothermal model and integrated in a system simulation software application in order to assess the effect of charging strategies and V2G on battery lifetime. When compared, LFP/C and NCA/C exhibited different behaviors when submitted to V2G scenarios. Light V2G scenarios led to a low aging for LFP/C based battery but tended to slightly increase the aging of NCA/C based battery according to simulations.

\section{Introduction}


In order to reduce fossil energy dependence and environmental impact of vehicles, new regulations encourage car manufacturers towards vehicle electrification. This electrification raises the issue of energy storage. Li-ion batteries are one of the most promising solutions to store the energy needed for highly electrified vehicles: hybrid electrical vehicles (HEV), plug-in hybrid vehicles (PHEV) or full electric vehicles (EV). However, energetic and power performance of Li-ion batteries is known to decrease during their service lifetime [1].

Although the cost of battery packs is decreasing [2], they comprise a significant proportion of market vehicle price, which means car manufacturers have to provide a guaranteed longevity ensuring a safe and sufficient battery performance throughout the vehicle service lifetime. Therefore, battery aging studies are of particular interest in order to optimize battery systems in terms of size and cooling requirements, and also to devise management strategies well suited along the vehicle lifetime. Providing a minimum level of performance is also mandatory to ensure financial viability for electrified vehicles. For such concerns, modeling is essential to provide car designers with information and reduce development costs.

While the main microscopic aging phenomena of Li-ion cells have been identified $[1,3]$ and described, for instance Li plating at low temperature [4], loss of active material at elevated temperature [5] or solid electrolyte interphase (SEI) growth at the negative electrode/electrolyte interface $[6,7]$, aging of Li-ion batteries remains difficult to predict $[8,9]$. In most aging models, considering that SEI growth is the main cause of aging for Li-ion batteries with graphite negative electrode leads to a quadratic evolution shape of the capacity loss in the beginning of the battery life as put forward by Spotnitz [10].

To find the main impact factors, research efforts have been dedicated to model macroscopic Liion cell capacity loss and impedance increase $[11,12]$. The main aging factors are the state of charge, SoC, the depth of discharge during cycle, $D o D$, the temperature, $T$, and current, $I$. Another key impact factor is the battery usage [13] which can be described in two contributions to aging : 
- Calendar aging $(I=0)$ : the battery is stored without being used so there is no current through the battery

- Cycle aging $(I \neq 0)$ : the battery is either charged or discharged.

It has been shown that the two types of aging will lead to different battery behaviors with usually a higher capacity loss and higher power loss during cycle aging [13].

In order to model aging phenomena, two different approaches have been put forward in the literature, which are physical modeling [14-16] and empirical modeling [10,17]. Usually empirical models will address either calendar aging $[10,13]$ or cycle aging [11]. Some other modeling works include both cycle and calendar aging behaviors [18-20] but the proposed model despite describing cycle aging does not take into account the charging rate on aging. The resulting model assesses the capacity loss as a function of time and constant stress factors which has little application in use. It is not convenient to use this kind of modeling for system simulation where stress factors are dynamically varying for instance due to environmental conditions (temperature variations due to seasons and day and night successions) or due to vehicle use (storage SoC depending on the duty cycle).

In this paper, an empirical capacity fade model suitable for system simulation application is described. This model has been calibrated for two Li-ion technologies and validated against experimental data and is used to assess the usefulness of different charging strategies in order to preserve the batteries' performance throughout their lifetime.

\section{Model development}

The capacity fade model is based on 2 contributions leading to different capacity losses in Ah:

$Q_{\text {loss }}^{\text {cal }}$ due to calendar aging and $Q_{\text {loss }}^{c y c}$ due to cycle aging. 


\subsection{Calendar aging}

As often discussed the two main stress factors for calendar aging are temperature and State of Charge. Usually $[11,21]$ an empirical aging law is given as below

$$
Q_{\text {loss }}^{\text {cal }}=B_{\text {cal }}(S O C) \exp \left(-\frac{E a_{\text {cal }}}{R T}\right) t^{z_{c a l}}
$$

In this expression $B_{c a l}$ is a pre-exponential factor depending on $S O C$, expressed in $\frac{A h}{s^{z} c a l}, E a_{c a l}$ is the activation energy, expressed in J.mol ${ }^{-1}$, which evaluates the dependency of calendar aging on temperature $T$, expressed in $\mathrm{K}$, and $z_{c a l}$ is a dimensionless constant. Considering a capacity loss phenomenon linked to SEI growth and diffusion limitations, this exponent should be around 0.5.

This expression is well suited to rapidly evaluate the capacity lost during long term storage but it is not suited when many different operating conditions are happening. As a consequence, this expression has been differentiated against time in order to evaluate infinitesimal variation of capacity due to calendar aging:

$$
\frac{d Q_{\text {loss }}^{\text {cal }}}{d t}=z_{\text {cal }} B_{\text {cal }}(S O C) \exp \left(-\frac{E a_{\text {cal }}}{R T}\right)\left(\frac{Q_{\text {loss }}^{\text {cal }}}{B_{\text {cal }}(S O C) \exp \left(-\frac{E a_{\text {cal }}}{R T}\right)}\right)^{1-\frac{1}{z_{c a l}}}
$$

This expression can then be linked to other capacity loss phenomena like cycle aging.

\subsection{Cycle aging}

For cycle aging a similar approach based on Wang et al. [11] is used. In this study the capacity loss due to aging is influenced by two major stress factors: current and temperature. The formulation encountered is then: 


$$
Q_{\text {loss }}^{c y c}=B_{c y c} \exp \left(\frac{-E a_{c y c}+\alpha|I|}{R T}\right) A h^{z_{c y c}}
$$

In this expression, $B_{c y c}$ is a pre exponential factor in $A h^{1-z_{c y c}}$ which depends on current, $E a_{c y c}$ is an activation energy for cycle aging expressed in $\mathrm{J}_{\mathrm{mol}}{ }^{-1}, \alpha$ is a coefficient for aging acceleration due to current expressed in J.mol ${ }^{-1} \cdot \mathrm{A}^{-1}, z_{c y c}$ is an exponent constant that should be around 0.5 for diffusion limited process. Finally, Ah stands for Ah throughput, that is the amount of charge sent into the cell. As it has been done for calendar aging, this expression has been differentiated against time:

$$
\frac{d Q_{\text {loss }}^{c y c}}{d t}=\frac{|I|}{3600} z_{c y c} B_{c y c}(I) \exp \left(\frac{-E a_{c y c}+\alpha|I|}{R T}\right)\left(\frac{Q_{\text {loss }}^{c y c}}{B_{c y c}(I) \exp \left(\frac{-E a_{c y c}+\alpha|I|}{R T}\right)}\right)^{1-\frac{1}{z_{c y c}}}
$$

In this expression, the Ah throughput term, once differentiated, is proportional to the current in the cell.

\subsection{Switch between calendar and cycle aging}

Once the influence on aging has been expressed for both behaviors, it is necessary to find a way to decide what kind of aging is occurring based on the actual operating conditions. The assumption here is that when the modeling of cycle aging has been performed, calendar aging occurring during cycle mode is already taken into account. As a consequence, we need to find a condition describing the switch between calendar and cycle mode.

First, taking as a major phenomenon of capacity loss the SEI formation at the negative electrode, it is known that the parasitic reaction of SEI formation is accelerated when the negative electrode potential is lower (i.e. during charge or when the SOC is high). As a consequence it has been assumed that cycle aging only occurs when the battery is in charge and the current is above a given threshold $I_{c y c}$ since higher charge current will lead to lower potential at the negative electrode. Furthermore, 
in order to assess the fact that diffusion in the cell tends to increase the overpotential when the charge is longer and then increases the rate of the SEI formation reaction, the current in $\frac{d Q_{\text {loss }}^{c y c}}{d t}$ expression (4) is replaced by a filtered current $\bar{I}$. As a consequence the total capacity loss is computed as follows:

$$
\frac{d Q_{\text {loss }}}{d t}=\left\{\begin{array}{l}
\frac{d Q_{\text {loss }}^{\text {cal }}}{d t} \Leftrightarrow \bar{I}<I_{\text {cyc }} \\
\frac{d Q_{\text {loss }}^{c y c}}{d t} \Leftrightarrow \bar{I}>I_{c y c}
\end{array}\right.
$$

This given threshold will depend on the battery ability to tackle high charging rates. For example high power batteries should have a high threshold around $1 \mathrm{C}$ current whereas high energy batteries designed for lower charging rates should have a lower threshold.

\subsection{Coupling with an electrothermal model of the battery behavior}

In order to get a global model of the electrothermal behavior of a Li-ion cell, it is necessary to couple this aging model with an electrothermal model. In Figure 1 are represented the inputs and outputs of both models as well as the coupling involved.

The electrothermal model evaluates the state of charge $(\mathrm{SOC})$, the voltage $\left(\mathrm{V}_{\text {cell }}\right)$ and the temperature $\left(T_{\text {cell }}\right)$ of the battery based on the input current $(I)$ and external temperature $\left(T_{a}\right)$. It provides the empirical aging model with the SOC and the $T_{\text {cell }}$ allowing it to evaluate the residual capacity $C_{\text {res }}$. This residual capacity is then used in the electrothermal model to evaluate the SOC as follows : 


$$
\operatorname{SOC}=\operatorname{SOC}_{0}+\frac{100}{3600} \int_{0}^{t} \frac{I}{C_{\text {res }}(t)} d t
$$

\section{Experimental validation}

\subsection{Calibration data}

In order to calibrate the empirical model presented in this paper, extensive experimental data are needed in order to get a wide range of operating conditions representative of the battery use. Experimental campaigns have been carried out by research groups in order to assess both cycle and calendar behavior of Li-ion batteries $[12,18,20-23]$. Two sets of calibration data are indeed necessary in order to take into account both types of aging. In these sets, experiments highlighting every stress factor are needed. As a consequence a significant amount of experimental data was needed and was collected in the literature for calendar aging [24] as well as for cycle aging [11,25].

Thanks to these data, it has been possible to calibrate the capacity loss model on two different battery technologies:

\section{- A123s 2.3 Ah LFP/C cell \\ - Saft VL6P 7 Ah NCA/C cell}

The parameters used for these technologies are indicated in Table 1. In the following section we will discuss in detail the validation for the A123s model.

\subsection{Validation of empirical model}

\subsubsection{Normalized profiles}


Extensive experimental studies from Savoye [26] have subjected an A123s 2.3 Ah cell to various cycle conditions in order to evaluate the cycling impact on Li-ion batteries aging. The aim was to discuss the aging impact in an automotive application and especially the impact of short current pulses on aging. The current profiles represented in Figure 2 are looped at $25^{\circ} \mathrm{C}$ and $45^{\circ} \mathrm{C}$ over more than 4000 cycles. These current profiles interestingly cover various cycle profiles with highly dynamic pulses at several different rates (ISO RMS and ISO MEAN), moderately dynamic pulses (DILATED) and slow solicitations (REFERENCE or 0.8 REFERENCE), as well as mixed solicitations (AT REST).

The comparison between experimental and simulation results using the empirical aging model described above is presented in Figure 3. It shows a good agreement between experimental results and simulations with less than $5 \%$ error for capacity loss lower than $20 \%$ except for the ISO MEAN condition where the model overestimates the capacity loss by $14 \%$. These results seem encouraging for using this model in automotive applications.

\subsubsection{Road profile}

In order to further validate the empirical model on actual data representative of vehicle use, aging measurements have been performed at cell level on IFPEN test benches [27]. Two different load profiles representative respectively of EV and HEV were looped. For the EV load profile (Figure 4-a), the program consisted of 4 charge depleting cycles followed by a constant current charge in order to get back to the initial SOC. The HEV load profile (Figure 4-b) consists of a charge-sustaining current profile which maintains the $\mathrm{SOC}$ around $60 \%$. The maximum current involved in the HEV profile is around $50 \mathrm{~A}$ whereas it remains lower than $20 \mathrm{~A}$ in the $\mathrm{EV}$ profile.

In Figure 5, it is possible to verify that the model is able to predict accurately capacity loss for both aging patterns (EV in Figure 5-a and HEV in Figure 5-b). It is then possible to use this model in automotive application. 


\section{Applications for lifetime prediction}

This capacity loss empirical model has been implemented in LMS Imagine. Lab Amesim ${ }^{\text {TM }}$ dedicated to system simulation. It can then be used in realistic operating conditions in order to adapt the charging strategies taking into consideration the long term issue of aging. In this scope we focused on a study that will discuss the impact of the recharge strategy of an electric vehicle fitted with a LFP-C battery or a NCA-C battery.

\section{1. $\quad$ Case studies}

Day to day use of an electric vehicle can be simplified with a common pattern comprising charging phases and trips from home to work and back. The base case which is considered in this study is the following:

- 4 home-work trips lasting 20 minutes at 8AM, 12PM, 1PM and 6PM.

In addition to these trips several charging and discharging phases are added. The discharging phase represents the vehicle connected to grid sections where the energy stored in the vehicle is used to relieve the grid during high demand periods. The constant charges and discharges are performed at a $40 \mathrm{~A}$ rate and stopped whenever the SOC reaches $10 \%$ or $90 \%$. As a consequence 5 test cases scenarios have been defined (Figure 6):

- The reference case consists in a classical daily use with a simple recharge when the driver comes back home.

- The "just in time" case consists in charging the car just before the first trip in the morning.

- During the "charge when you can" case the driver tries to charge the car whenever he has time to do so (that is after every trip except when he gets back home for lunch).

- The "strong V2G" scenario consists in a discharge of the car when there is time (at 9AM, 2PM and 19PM) and a recharge when the battery is empty before leaving (6AM, 11AM, 4PM). As a consequence, the battery is mostly stored at a low SoC (10\%). 
- The "light V2G" scenario is only considering a discharge of the battery when the driver comes back home at the end of the day.

These test case scenarios deal with two main stress factors regarding aging, which are current inside the cells and the SOC. Another stress factor of aging to be accounted for is the temperature. Figure 7 illustrates the temperature variations seen by the battery during a year in this case study. There is in fact a double temperature variation. External temperature is submitted to a daily variation due to days and nights but also to an annual variation due to seasons. Moreover, the use of the battery leads to a temperature increase due to heat losses. As can be seen in the prediction of battery daily temperature variations some small peaks mark a battery self-heating of 1 or $2^{\circ} \mathrm{C}$ under the hypothesis of an efficient thermal exchange leading to an exchange coefficient of $50 \mathrm{~W} / \mathrm{m}^{2} / \mathrm{K}$.

\section{2. $\quad$ Results}

Simulations have been performed on both LFP/C and NCA/C packs whose properties are given in Table 2. The aim was to build a battery pack with the same capacity. However due to the differences between the nominal voltage and inherent properties of the cells such as internal resistance, the pack power and energy are different.

The simulation evaluates the aging of the batteries during one year use considering that the profile patterns described in Figure 6 occur every day. In Figure 8 are represented the capacity losses for both technologies for every test case.

Due to the sizing differences between both packs, we will not focus on the comparison of the raw performances of both technologies but rather on the differences that can be seen between the test case behaviors.

For both cells, the best scenario is the "just in time" case. In this scenario, the cell remains at low SOC during the night, reducing the calendar aging effect compared to the reference case where it is 
stored at $90 \%$ SOC. It is even more visible in the "charge when you can" scenario for the LFP/C based battery where the cell is always stored at $100 \%$ SOC increasing capacity loss during storage. Yet the "strong V2G" scenario where the battery is always stored at $10 \%$ SOC is not so good compared with the reference case for both technologies. In this case the advantage from storage at low SOC is outweighed due to the need to recharge the battery to $100 \%$ SOC before every use. This recharge causes a higher cycle aging capacity loss and thus a premature aging.

However, the behavior seen in the case of a LFP/C based battery is different from the one encountered with a NCA/C based battery where the aging of the "charge when you can" scenario is slightly bigger than the reference case but stays in the same order of magnitude. Moreover it clearly appears that in the case of the NCA/C based pack, the V2G scenarios lead to a premature aging of the battery ( $4 \%$ loss for the strong V2G and $2.8 \%$ for light $\mathrm{V} 2 \mathrm{G}$ ) and are even worse than the "charge when you can" scenario ( $2.7 \%$ loss) whereas this last scenario is the worst one in the LFP/C based battery case ( $7.6 \%$ loss) and the light V2G is the second best scenario for the LFP/C battery on par with the "just in time" case (around 3.5\% loss). It seems that the NCA/C based battery studied here is more sensitive to cycle aging than calendar aging. Then it will perform worse when submitted to frequent charges (eg. during V2G and "charge when you can" scenarios).

As a consequence, both technologies exhibit clearly different behaviors when submitted to the same test cases. Based on these simulations, advice for vehicle use and especially recommendation on V2G applications will be different depending on the technology used to build the battery pack.

\section{Conclusion}

An empirical capacity aging model for Li-ion batteries has been developed. It is coupled with an electrothermal model and accounts for both types of aging encountered during Li-ion battery life: calendar aging and cycle aging. Thanks to an extensive experimental campaign and data mining it has been possible to calibrate and validate the model for two different Li-ion technologies. Once 
validated, the model has been integrated in a system simulation software application in order to assess the behavior of the cells when submitted to various test case scenarios. These simulations showed some major differences between both technologies, the NCA/C based battery proved to be more sensitive to cycle aging compared to the LFP/C cell leading to a premature aging when submitted to frequent charges of the V2G scenarios.

This approach proved to be appropriate in order to evaluate the charging strategies that could be applied to an electrical vehicle in order to reduce its aging and in doing so increase its lifetime and cost efficiency. It is then able to accurately model the specific behaviors of both cells used in this study leading to recommend a light V2G strategy for the LFP/C based cell when it should rather be avoided in the case of the NCA/C based battery.

This study only focuses on the capacity loss due to aging. However, it is known that batteries also exhibit resistance increase. This increase has been neglected here since in the case of both cells used this resistance increase remained low even at the end of life. However, for other cells this may not be the case. As a consequence further work should be done in order to apply this approach for power loss.

\section{References}

[1] J. Vetter, P. Novak, M.R. Wagner, C. Veit, K.C. Moller, J.O. Besenhard, M. Winter, M. Wohlfahrt-Mehrens, C. Vogler, A. Hammouche, J.Power Sources 147 (2005) 269-281.

[2] B. Nykvist, M. Nilsson, Nature Climate change 5 (2015) 329-332.

[3] M. Broussely, P. Biensan, F. Bonhomme, P. Blanchard, S. Herreyre, K. Nechev, R.J. Staniewicz, J.Power Sources 146 (2005) 90-96.

[4] N. Legrand, B. Knosp, P. Desprez, F. Lapicque, S. Raël, J.Power Sources 245 (2014) 208-216.

[5] Q. Zhang, Q. Guo, R.E. White, J.Power Sources 165 (2007) 427-435.

[6] M. Kassem, J. Bernard, R. Revel, S. Pélissier, F. Duclaud, C. Delacourt, J.Power Sources 208 (2012) $296-305$. 
[7] M. Kassem, C. Delacourt, J.Power Sources 235 (2013) 159-171.

[8] J. Groot, M. Swierczynski, A.I. Stan, S.K. Kær, J.Power Sources 286 (2015) 475-487.

[9] M. Klett, R. Eriksson, J. Groot, P. Svens, K.C. Högström, R.W. Lindstöm, H. Berg, T. Gustafson, G. Lindbergh, K. Edström, J.Power Sources 257 (2014) 126-137.

[10] Spotnitz R., I.Power Sources 113 (2003) 72-80.

[11] J. Wang, P. Liu, J. Hicks-Garner, E. Sherman, S. Soukiazian, M. Verbrugge, H. Tataria, J. Musser, P. Finamore, J.Power Sources 196 (2011) 3942-3948.

[12] M. Ecker, N. Nieto, S. Käbitz, J. Schmalstieg, H. Blanke, A. Warnecke, D.U. Sauer, J.Power Sources 248 (2014) 839-851.

[13] I. Bloom, B.G. Potter, C.S. Johnson, K.L. Gering, J.P. Christophersen, J.Power Sources 155 (2006) 415-419.

[14] J. Newman, K.E. Thomas-Alyea, Electrochemical Systems (3rd ed.), John Wiley \& Sons, Inc, Hoboken, New Jersey, 2004.

[15] E. Prada, D. Di Domenico, Y. Creff, J. Bernard, V. Sauvant-Moynot, F. Huet, J.Electrochem.Soc. 160 (2013) A616-A628.

[16] M. Safari, M. Morcrette, A. Teyssot, C. Delacourt, J.Electrochem.Soc. 156 (2009) A145-A153.

[17] M. Broussely, S. Herreyre, P. Biensan, P. Kasztejna, K. Nechev, R.J. Staniewicz, J.Power Sources 97-98 (2001) 1.3-21.

[18] J. Belt, V. Utgikar, I. Bloom, J.Power Sources 196 (2011) 10213-10221.

[19] M. Ecker, J.B. Gerschler, J. Vogel, S. Käbitz, F. Hust, P. Dechent, D.U. Sauer, J.Power Sources 215 (2012) $248-257$.

[20] J. Schmalstieg, S. Kabitz, M. Ecker, D.U. Sauer, pp. 1-1.2.

[21] I. Bloom, B.W. Cole, J.J. Sohn, S.A. Jones, E.G. Polzin, V.S. Battaglia, G.L. Henriksen, C. Motloch, R. Richardson, T. Unkelhaeuser, D. Ingersoll, H.L. Case, J.Power Sources 101 (2001) 238-247.

[22] R.G. Jungst, G. Nagasubramanian, H.L. Case, B.Y. Liaw, A. Urbina, T.L. Paez, D.H. Doughty, J.Power Sources 119-121 (2003) 870-873.

[23] R.B. Wright, C.G. Motloch, J.R. Belt, J.P. Christophersen, C.D. Ho, R.A. Richardson, I. Bloom, S.A. Jones, V.S. Battaglia, G.L. Henriksen, T. Unkelhaeuser, D. Ingersoll, H.L. Case, S.A. Rogers, R.A. Sutula, J.Power Sources 110 (2002) 445-470.

[24] S. Grolleau, B. Molina-Concha, A. Delaille, R. Revel, J. Bernard, S. Pelissier, J. Peter, ECS Transactions 45 (2013) 73-81.

[25] P. Gyan, P. Aubret, J. Hafsaoui, F. Sellier, S. Bourlot, S. Zinola, F. Badin, Oil and Gas Science and Technology - Rev.IFP Energies nouvelles 68 (2013) 137-147.

[26] F. Savoye, Impact des impulsions périodiques de courant sur la performance et la durée de vie des accumulateurs lithium-ion et conséquences de leur mise en œuvre dans une application transport. PhD, Laboratoire Ampère, 2012.

[27] J. Bernard, R. Revel, D. Audigier, in: Batteries: The International Energy \& Power Supply conference and Exhibition, 2013. 



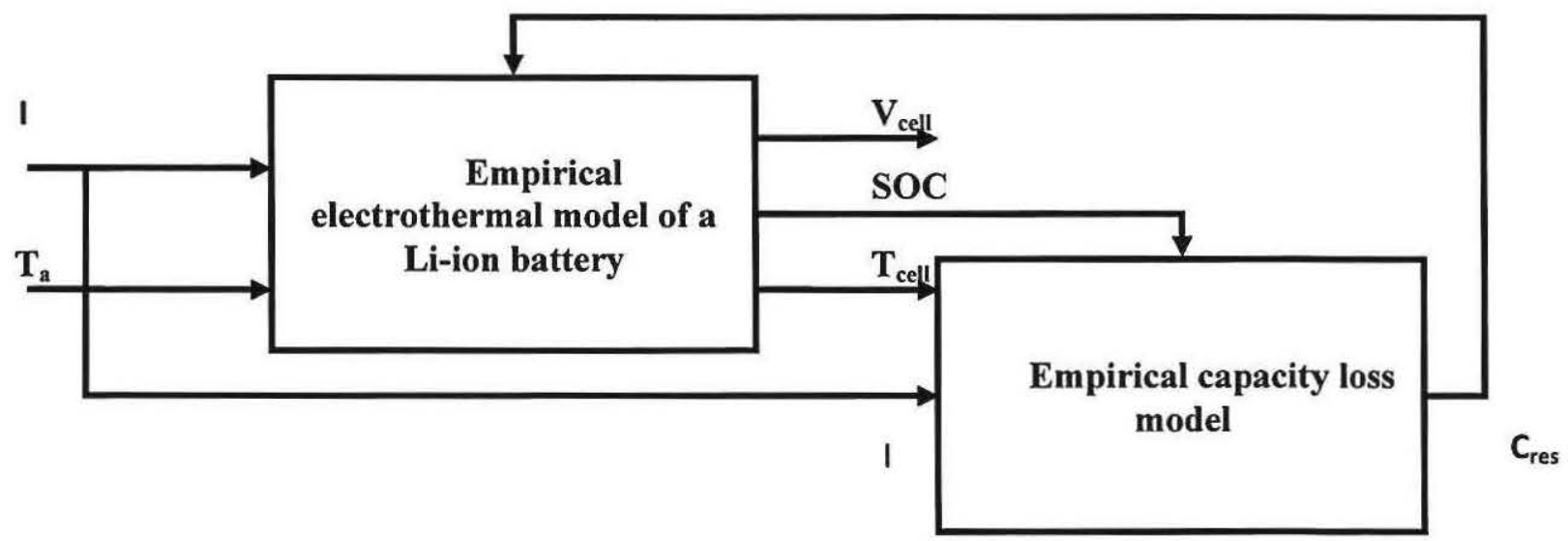

Figure 1: Representation of the coupling between an electrothermal model and the empirical aging model 

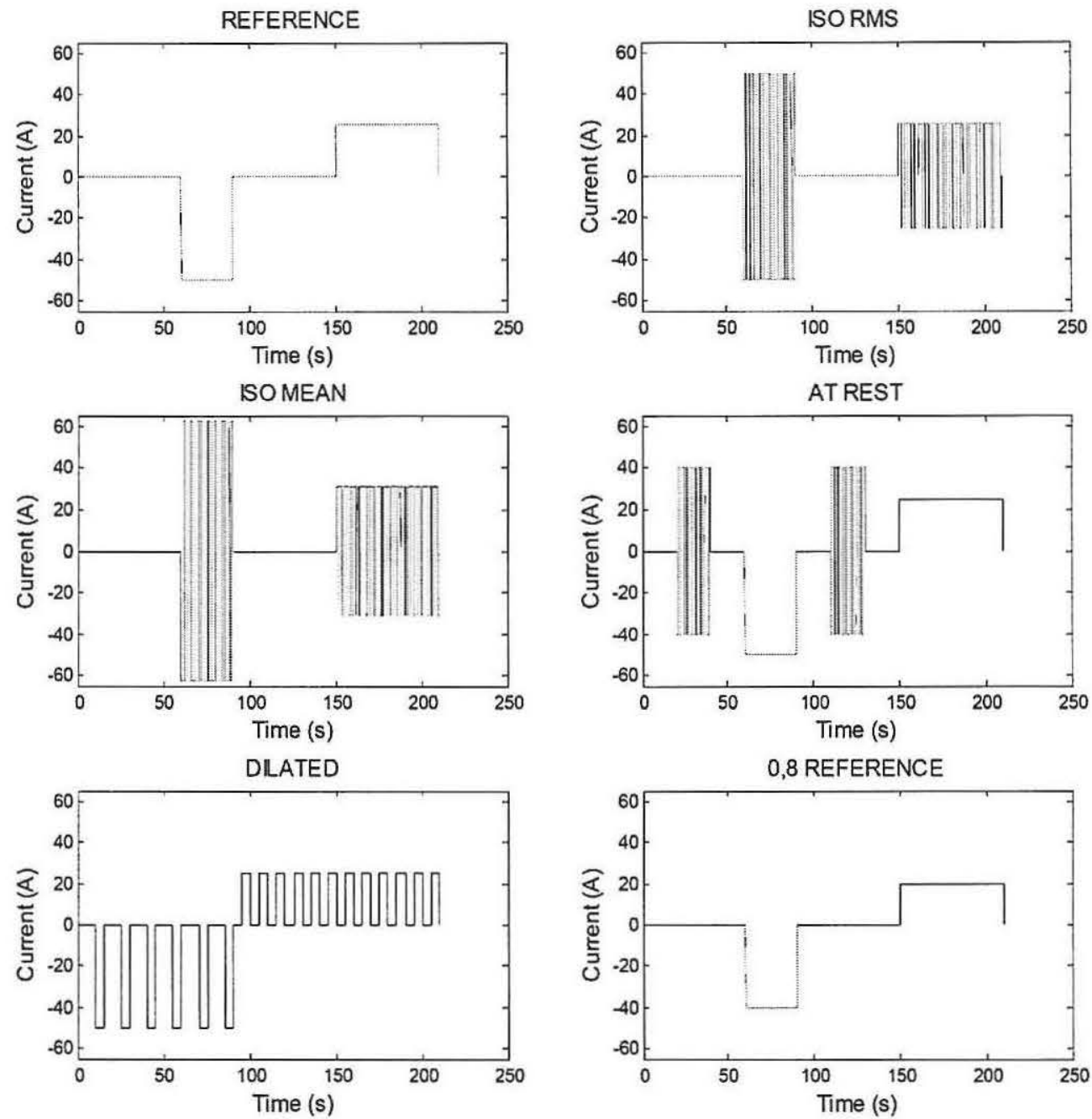

Figure 2: Current profile taken from Savoye [26] 

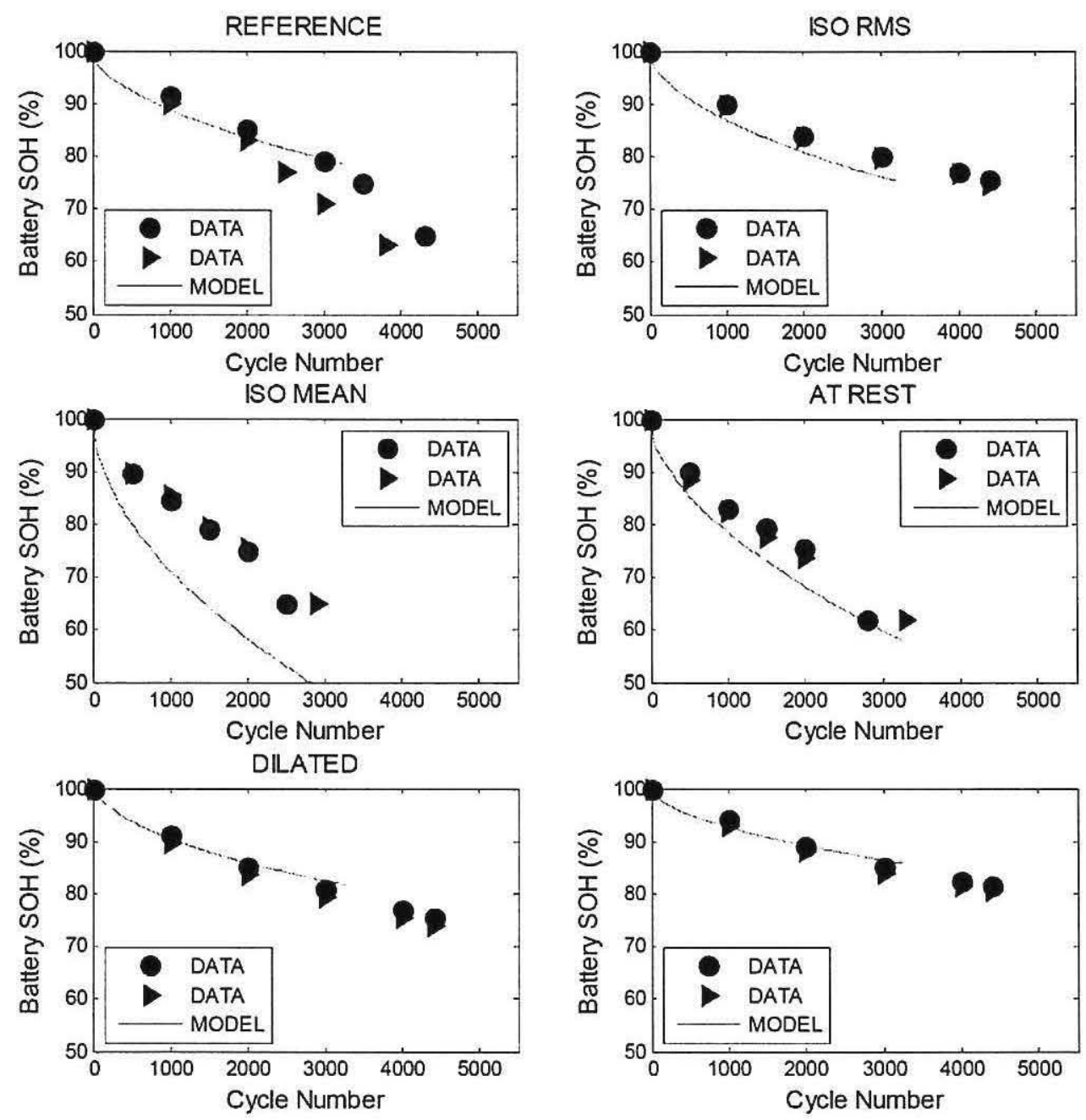

Figure 3: Comparison between experimental data from Savoye [26] and simulation results 

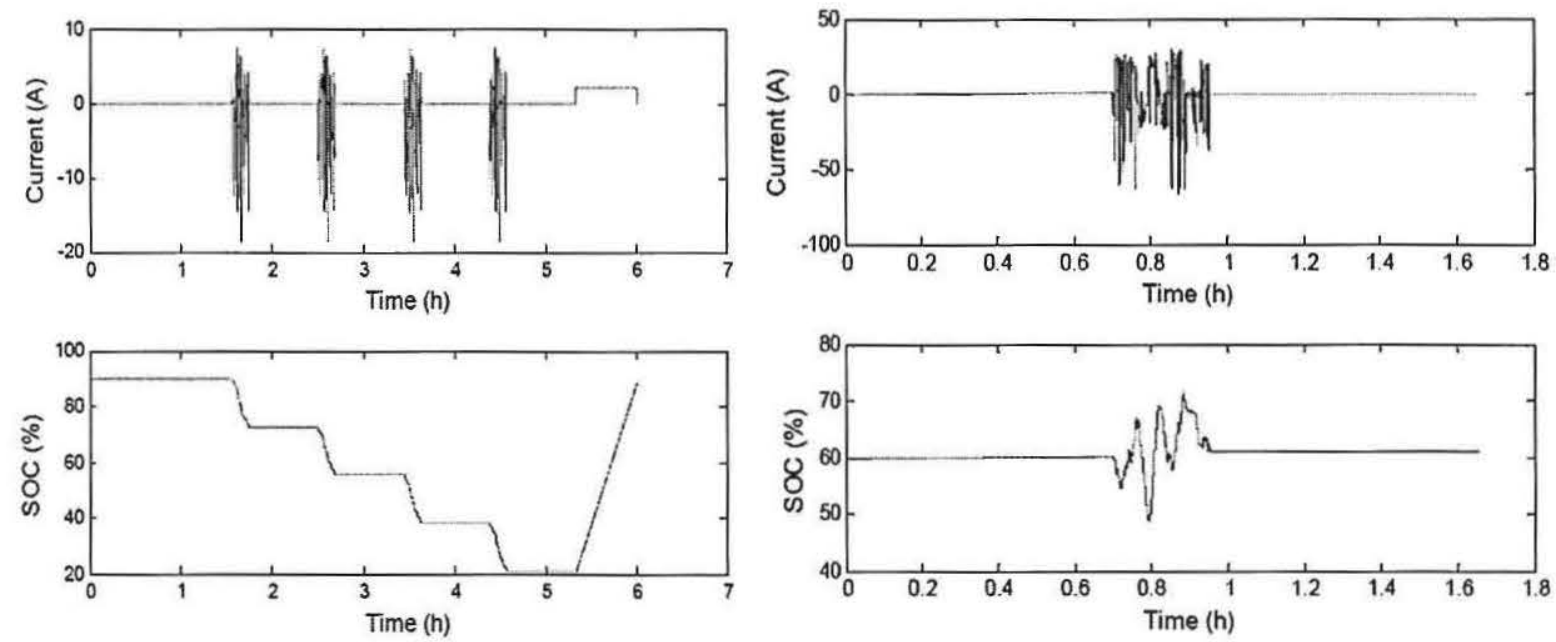

(a) Current load profile representative for an EV and subsequent SOC profile

(b) Current load profile representative for an HEV and subsequent SOC profile

Figure 4: Current profile used for EV and HEV validation 


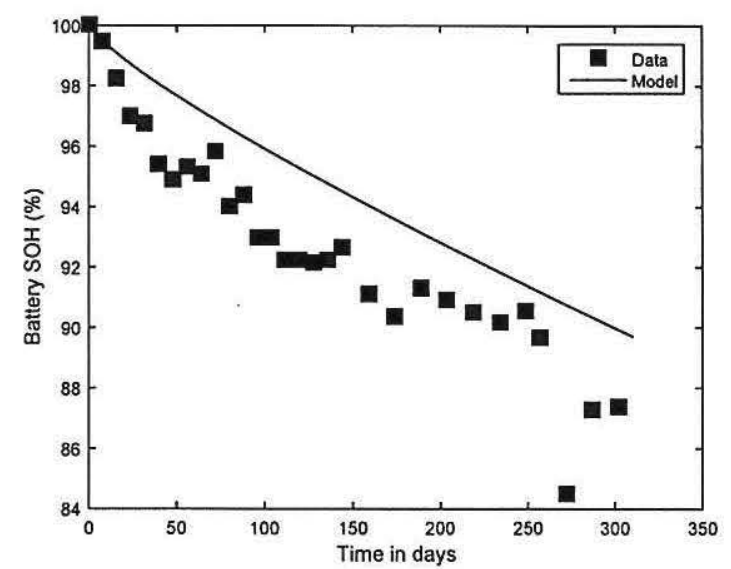

(a) EV aging

Figure 5: Comparison between experimental data and simulation results

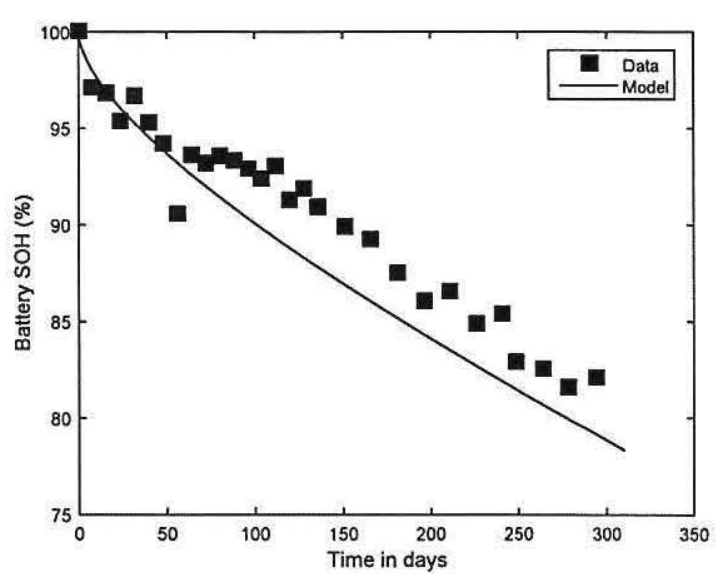

(b) HEV aging 

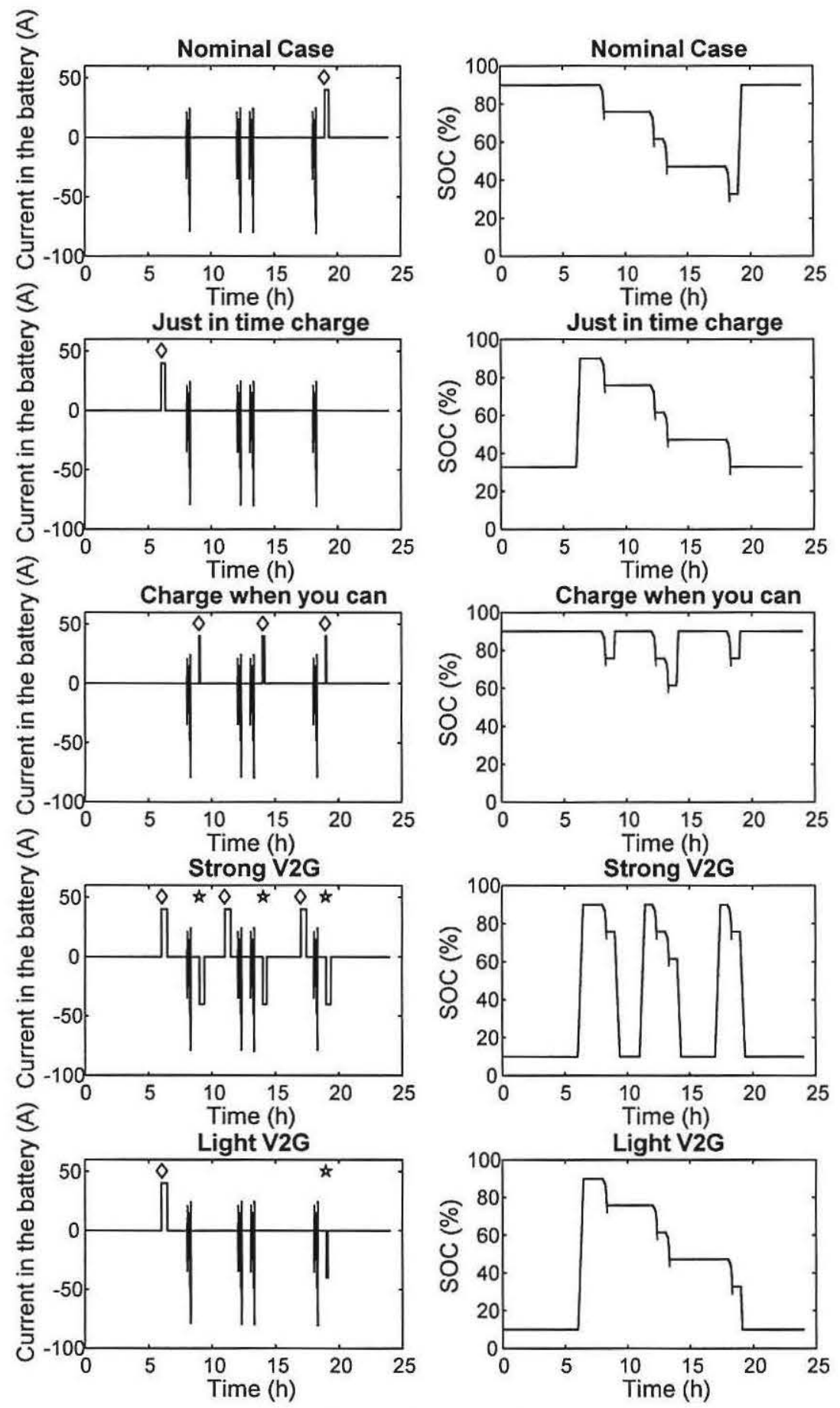

$$
\begin{array}{ll} 
& \text { Power demand } \\
\star & \text { V2G } \\
\diamond & \text { G2V }
\end{array}
$$

Figure 6: Current and SOC profiles during test case scenarios 

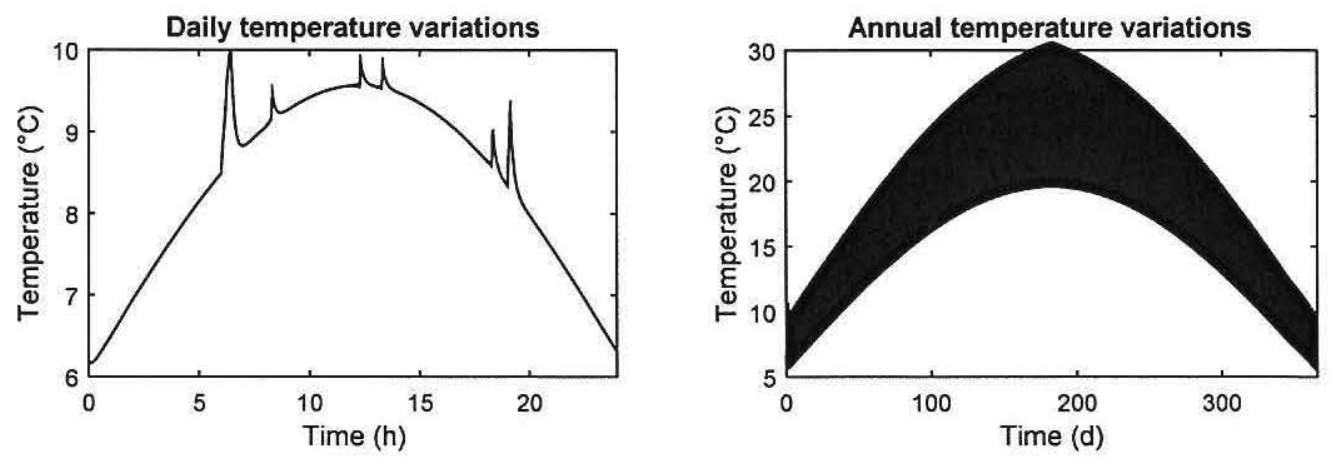

Figure 7: Temperature variations during simulation 
Table 1: Parameters of the empirical aging model

\begin{tabular}{|c|c|c|c|c|c|c|c|c|c|}
\hline & \multicolumn{5}{|c|}{ A123s 2,3 Ah } & \multicolumn{3}{|l|}{ Saft VL6P } \\
\hline \multirow{6}{*}{ 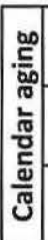 } & \multirow[t]{2}{*}{$B_{c a l}(S O C)$} & \multicolumn{2}{|c|}{$30 \%$} & \multicolumn{2}{|c|}{$65 \%$} & $100 \%$ & $30 \%$ & $65 \%$ & $100 \%$ \\
\hline & & \multicolumn{2}{|c|}{734063} & \multicolumn{2}{|c|}{675334} & 218211 & $2.78 \cdot 10^{5}$ & $3.80 \cdot 10^{5}$ & $5.43 \cdot 10^{5}$ \\
\hline & \multirow[t]{2}{*}{$E a_{c a l}(S O C)$} & \multicolumn{2}{|c|}{$30 \%$} & \multicolumn{2}{|c|}{$65 \%$} & $100 \%$ & \multirow{2}{*}{\multicolumn{3}{|c|}{52862}} \\
\hline & & \multicolumn{2}{|c|}{$73369 \mathrm{~J} / \mathrm{mol}$} & \multicolumn{2}{|c|}{$69804 \mathrm{~J} / \mathrm{mol}$} & $56937 \mathrm{~J} / \mathrm{mol}$ & & & \\
\hline & \multirow[t]{2}{*}{$z_{c a l}(S O C)$} & \multirow{2}{*}{\multicolumn{2}{|c|}{$\begin{array}{c}30 \% \\
0.943\end{array}$}} & \multicolumn{2}{|c|}{$65 \%$} & $100 \%$ & \multirow{2}{*}{\multicolumn{2}{|c|}{0.52}} & \\
\hline & & & & \multicolumn{2}{|c|}{0.900} & 0.683 & & & \\
\hline \multirow{7}{*}{ 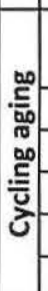 } & \multirow[t]{2}{*}{$B_{c y c}(I)$} & $1 \mathrm{~A}$ & 4 & & $12 \mathrm{~A}$ & $20 \mathrm{~A}$ & \multirow{2}{*}{\multicolumn{2}{|c|}{130}} & \\
\hline & & $3.16 \cdot 10^{3}$ & & $\cdot 10^{4}$ & 1.29 . & $1.55 \cdot 10^{4}$ & & & \\
\hline & $E a_{c y c}$ & \multicolumn{5}{|l|}{$31700 \mathrm{~J} / \mathrm{mol}$} & \multicolumn{3}{|l|}{$18461 \mathrm{~J} / \mathrm{mol}$} \\
\hline & $Z_{c y c}$ & \multicolumn{5}{|l|}{0.55} & \multicolumn{3}{|l|}{0.4} \\
\hline & $\alpha_{c y c}$ & \multicolumn{5}{|l|}{370.3} & \multicolumn{3}{|l|}{32} \\
\hline & $I_{c y c}$ & \multicolumn{5}{|l|}{$1 \mathrm{C}$} & \multicolumn{3}{|l|}{$1 \mathrm{C}$} \\
\hline & $\tau_{\text {filt }}$ & \multicolumn{5}{|l|}{$60 \mathrm{~s}$} & \multicolumn{3}{|l|}{$0 \mathrm{~s}$} \\
\hline
\end{tabular}


Table 2: Battery pack properties for simulations

\begin{tabular}{|l|l|l|}
\hline Chemistry of battery cells & LFP/C & NCA/C \\
\hline Capacity of the battery & $2.3 \mathrm{Ah}$ & $2.3 \mathrm{Ah}$ \\
\hline Number of cells in series & 100 & 100 \\
\hline Number of parallel branches & 10 & 10 \\
\hline Power of the pack & $384 \mathrm{~kW}$ & $189 \mathrm{~kW}$ \\
\hline Energy of the Pack & $7600 \mathrm{Wh}$ & $8280 \mathrm{Wh}$ \\
\hline Nominal Voltage of the pack & $320 \mathrm{~V}$ & $360 \mathrm{~V}$ \\
\hline
\end{tabular}




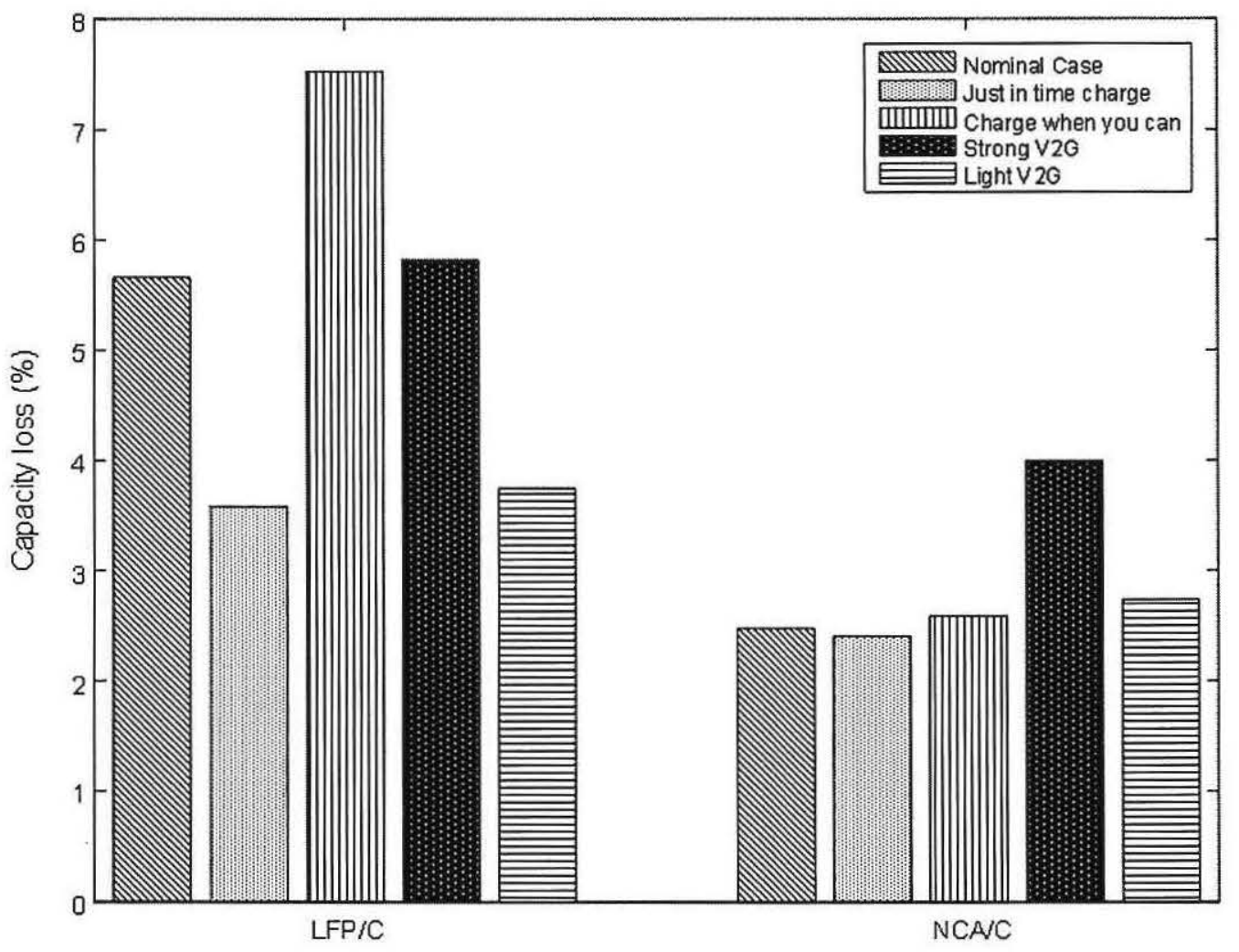

Figure 8: Capacity loss for both battery technologies after $\mathbf{1}$ year cycle according to every scenario 